\title{
Investigating the effects of differently produced synthetic amorphous silica (E 551) on the integrity and functionality of the human intestinal barrier using an advanced in vitro co-culture model
}

\author{
Claudia Hempt ${ }^{1,2} \cdot$ Cordula Hirsch $^{1}\left(\mathbb{D} \cdot\right.$ Yvette Hannig $^{1} \cdot$ Alexandra Rippl $^{1} \cdot$ Peter Wick $^{1}$ (1) $\cdot$ Tina Buerki-Thurnherr $^{1}(\mathbb{D})$
}

Received: 21 August 2020 / Accepted: 19 November 2020 / Published online: 15 December 2020

(c) The Author(s) 2020

\begin{abstract}
E 551, also known as synthetic amorphous silica (SAS), is the second most produced food additive. However, according to the re-evaluation of E 551 by the European Food Safety Authority (EFSA) in 2018, the amount of available data on the oral toxicity of food grade E 551 is still insufficient for reliable risk assessment. To close this gap, this study aimed to investigate six food-grade SAS with distinct physicochemical properties on their interaction with the intestinal barrier using advanced in vitro intestinal co-cultures and to identify potential structure-activity relationships. A mucus-secreting Caco-2/HT-29/ Raji co-culture model was treated with up to $50 \mu \mathrm{g} / \mathrm{ml} \mathrm{SAS} \mathrm{for} 48 \mathrm{~h}$, which represents a dose range relevant to dietary exposure. No effects on cell viability, barrier integrity, microvilli function or the release of inflammatory cytokine were detected after acute exposure. Slight biological responses were observed for few SAS materials on iron uptake and gene expression levels of mucin 1 and G-protein coupled receptor 120 (GPR120). There was no clear correlation between SAS properties (single or combined) and the observed biological responses. Overall, this study provides novel insights into the short-term impact of food-relevant SAS with distinct characteristics on the intestinal epithelium including a range of intestine-specific functional endpoints. In addition, it highlights the importance of using advanced intestinal co-cultures embracing relevant cell types as well as a protective mucus barrier to achieve a comprehensive understanding of the biological response of food additives at the intestinal barrier in vitro.
\end{abstract}

Keywords Synthetic amorphous silica (E551) - Intestinal co-cultures $\cdot$ In vitro toxicology $\cdot$ Structure-activity relationships $\cdot$ Intestine-specific functional endpoints

\section{Introduction}

Over the last years, the European Food Safety Authority (EFSA) has re-evaluated many food additives (EFSA, 2015, 2016a, b, c, d, 2017a, b, 2018a, b). This included synthetic amorphous silica (SAS), which are defined as nanostructured

Electronic supplementary material The online version of this article (https://doi.org/10.1007/s00204-020-02957-2) contains supplementary material, which is available to authorized users.

Tina Buerki-Thurnherr

tina.buerki@empa.ch

1 Laboratory for Particles-Biology Interactions, Empa, Swiss Federal Laboratories for Materials Science and Technology, Lerchenfeldstrasse 5, 9014 St. Gallen, Switzerland

2 Department of Health Sciences and Technology, ETH Zürich, Zürich, Switzerland materials (Bosch et al. 2012). They are registered in the European Union under E 551 (European Commission 2008). SAS are processing agents, which can be added to food and non-food products as an anti-caking agent, flow aid, clearing agent or stabiliser (EU 2008; OECD 2004; Van Kesteren et al. 2015).

A considerable amount of toxicity assessments of silica materials has already been performed in in vitro as well as in animal models with slightly varying outcomes (FruijtierPölloth 2016). An in vivo study in rodents indicated that oral exposure to food-grade SAS (E 551) did not induce systemic toxicity or immunotoxicity (Van der Zande et al. 2014). In contrast, fumed silica induced cytotoxic responses in bronchial epithelial cells and macrophages in vitro (Zhang et al. 2012). It is often difficult to compare different studies and to draw firm conclusions on the safety of food grade SAS as many of these toxicity studies do not specify what type of silica has been used, and even silica materials that 
are not authorized as E 551 were included in the evaluation (Fruijtier-Pölloth, 2016; Sohal et al. 2018). It has been pointed out by the European Food Safety Authority (EFSA) as well as Maynard (2014) that more data are needed to fully evaluate SAS (EFSA, 2018a). The EFSA hinted that the unique characteristics of the different SAS forms (precipitated, gel, pyrogenic and colloidal, while the colloidal is not authorized as E 551) may alter their behaviour (EFSA, 2018a). For instance, Zhang et al. (2012) found a higher toxicity for fumed compared to colloidal silica and postulated that this was due to the presence of siloxane rings in fumed silica. Therefore, the use of food-grade SAS and a comprehensive characterisation of the used materials is pivotal to identify structure-activity relationships. Moreover, Sohal et al. (2020) suggested to perform a full toxicity evaluation of SAS in vitro in advanced intestinal co-culture models and to cover not only conventional toxicity endpoints (e.g., cell viability, oxidative stress and pro-inflammatory responses) but also address potential functional changes of the intestinal barrier. Endpoints to assess physiological functions of the intestine in vitro have only recently started to be investigated for $\mathrm{TiO}_{2}$ and $\mathrm{SiO}_{2}$ nanomaterials such as the uptake of iron, glucose or lipids (Guo et al. 2018, 2017). Moreover, a recent paper on the translocation of E 551 in an in vitro intestinal model suggested different intestinal transport mechanism for E 551 and nano-sized $\mathrm{SiO}_{2}$ resulting in an overall transport of $1.4-1.6 \%$ for $\mathrm{E} 551$ and $3.6 \%$ for nano-sized $\mathrm{SiO}_{2}$, respectively (Yu et al. 2020).

A prevalent $2 \mathrm{D}$ model to study toxicity at the intestinal barrier is the human colorectal adenocarcinoma Caco-2 cells, which form a polarised epithelial monolayer with a microvilli brush border on a semipermeable insert (Jumarie and Malo 1991). However, differentiated Caco-2 monolayers poorly represent the complex anatomical and physiological situation of the intestine and lack the mucus layer, which constitutes an important mechanical and chemical barrier (Chopra et al. 2010).

The improvement of intestinal cultures by including multiple relevant human intestinal cell types as well as a confluent mucus layer presents a promising approach towards a more predictive in vitro toxicity assessment of food relevant materials. In the recent years, intestinal organoid culture (Brandenberg et al. 2020; Sato et al. 2009) and highly advanced co-cultures (Antunes et al. 2013; GarcíaRodríguez et al. 2018a; Schimpel et al. 2014) have been established. The advanced co-cultures have been successfully developed to express a mucus barrier and/or contain the most common cell types of the intestine (e.g., enterocytes, goblet cells, M-cells) (Antunes et al. 2013; GarcíaRodríguez et al. 2018a; Schimpel et al. 2014). Indeed, incorporation of M-cells has been proven to be critical to achieve predictive results for nanomaterial uptake since the fate of nanomaterials in the gastro intestinal tract (GIT) is very much driven by these cells (Powell et al. 2010). These advanced intestinal co-cultures could also be very useful to assess the toxicity of food compounds and additives on viability, integrity and physiological function of the intestinal barrier. However, suitable assays need to be identified that are compatible with these advanced co-cultures, in particular since the presence of a dense mucus layer could interfere with conventional toxicity assays.

In a previous study, we have investigated the deposited dose and acute toxicity of 10 food-grade SAS materials of commercial relevance in differentiated Caco- 2 monolayers (Hempt et al. 2020). We did not observe any considerable acute toxicity of the different SAS materials independent of the production process and the material properties. This type of studies, including relatively simple monoculture models and few acute toxicity endpoints, are interesting for a first screening of a large variety of (nano)materials. However, the use of more advanced intestinal co-culture models and inclusion of sensitive functional cellular assays is pivotal to achieve a more comprehensive understanding of (nano)material interactions at the intestinal barrier. Here, we applied an advanced in vitro intestinal model (Caco-2/HT-29-MTXE12/Raji B) with a confluent mucus layer and M-cells to investigate the impact of six food-grade SAS materials to identify potential structure-activity relationships. These six nanostructured materials differ in aggregate size, surface area, silanol content and production route. This study especially focused on the evaluation of intestine-specific functional effects like mucus coverage, microvilli function, lipid uptake, iron uptake and barrier integrity besides more conventional viability and inflammatory responses.

\section{Material and methods}

\section{Particle synthesis, dispersion and characterisation}

Six food grade SAS materials were kindly provided by Evonik Operations GmbH (Hanau, Germany). These included precipitated silica produced by wet process (SIPERNAT ${ }^{\circledR}$ materials) as well as fumed silica produced by flame hydrolysis (AEROSIL ${ }^{\circledR}$ materials) (EFSA 2018a; IPTS/EC 2007). An extensive characterisation of these SAS has been performed in our previous publication (Hempt et al. 2020) and a summary of the particle characteristics is provided in Table 1.

Surface hydroxyl concentrations of SAS were provided by Evonik Operations GmbH (Hanau, Germany) and were estimated by reaction with lithium aluminium hydride (lithiumalanate, $\mathrm{LiAlH}_{4}$ ). Briefly, hydrogen evolving by reaction of $\mathrm{LiAlH}_{4}$ with the surface hydroxyl groups (see Eq. 1) was measured and the silanol density was calculated according to Eq. 2: 


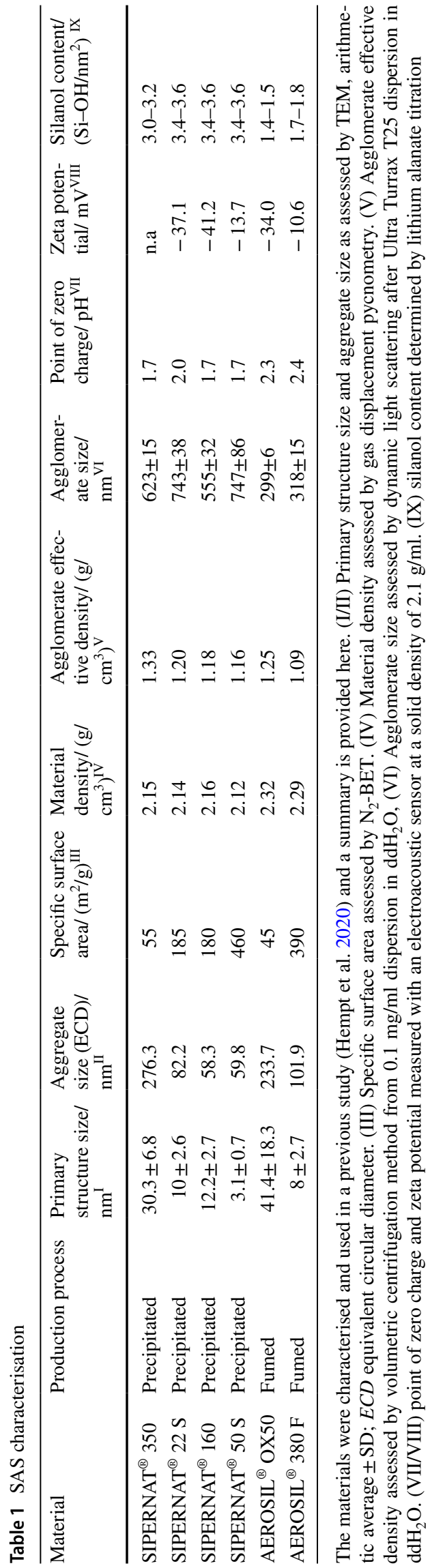

$$
\begin{gathered}
4 \equiv \mathrm{Si}-\mathrm{OH}+\mathrm{LiAlH}_{4} \rightarrow \equiv \mathrm{Si}-\mathrm{O} \\
-\mathrm{Li}+(\equiv \mathrm{Si}-\mathrm{O})_{3} \mathrm{Al}+4 \mathrm{H}_{2} \\
\mathrm{OH} / \mathrm{nm}^{2}=\frac{\frac{\mathrm{V}_{\mathrm{H} 2} \times \mathrm{p}}{\mathrm{R} \times \mathrm{T}} \mathrm{N}_{\mathrm{A}}}{10^{24} \times \mathrm{SSA} \times \mathrm{m}},
\end{gathered}
$$

where $V_{H 2}$ is the hydrogen volume $(\mathrm{ml}), p$ the pressure $(\mathrm{Pa})$, $\mathrm{T}$ the temperature $(\mathrm{K})$, SSA the specific surface area $\left(\mathrm{m}^{2} / \mathrm{g}\right)$ and $\mathrm{m}$ the sample mass $(\mathrm{g}) . \mathrm{N}_{\mathrm{A}}$ and $\mathrm{R}$ are the Avogadro and the ideal gas constant, respectively.

No acid pre-treatment was performed since it has been shown that it did not alter the characteristics of the SAS materials (Maier et al. 2013).

Stock dispersions of SAS $(10 \mathrm{mg} / \mathrm{ml})$ were prepared as previously described (Hempt et al. 2020) in double distilled water $\left(\mathrm{ddH}_{2} \mathrm{O}\right)$ using an ULTRA-TURRAX ${ }^{\circledR}$ T25 (IKA, Staufen, Germany) at 14,600 rpm for $1 \mathrm{~min}$, which results in a particle size distribution found in food matrix (Contado et al. 2013; Maier et al. 2015 as cited in EFSA et al. 2018). Stock dispersions were stored at room temperature (RT) for up to 12 weeks and treated again with ULTRA-TURRAX ${ }^{\circledR}$ prior to any SAS treatment.

\section{Cell culture}

The human colorectal adenocarcinoma cell line Caco-2 was obtained from the German collection of microorganisms and cell cultures (DSMZ, Braunschweig, Germany). Cells were maintained in Minimum Essential Medium (MEM) (Sigma) supplemented with $10 \%$ fetal calf serum (FCS), $2 \mathrm{mM}$ L-glutamine, $1 \%(\mathrm{v} / \mathrm{v})$ penicillin, streptomycin, neomycin (PSN) and $1 \%(\mathrm{v} / \mathrm{v})$ non-essential amino acids (all from Sigma) (hereafter called "complete MEM") at $37{ }^{\circ} \mathrm{C}, 5 \%$ $\mathrm{CO}_{2}$ and $95 \%$ humidity, hereafter called "standard growth conditions". Caco- 2 cells were grown in $75 \mathrm{~cm}^{2}$ cell culture flasks (TPP) until reaching $80 \%$ confluence and subcultured using trypsin-EDTA (Sigma). The human colon cell line HT-29-MTX-E12 (hereafter called "HT-29") was obtained from the European Collection of Authenticated Cell Cultures (ECACC, England). HT-29 were maintained in Dulbecco's Modified Eagle Medium (DMEM) (Sigma), supplemented with $10 \%$ FCS, $2 \mathrm{mM}$ L-glutamine, 1\% (v/v) PSN and 1\% (v/v) non-essential amino acids (all from Sigma) (hereafter called "complete DMEM") at standard growth conditions. HT-29 cells were grown in $75 \mathrm{~cm}^{2}$ cell culture flasks (TPP) until reaching $80 \%$ confluence and subcultured using trypsin-EDTA (Sigma). The human B lymphocyte cell line Raji (ATCC ${ }^{\circledR}$ CCL-86 ${ }^{\mathrm{TM}}$ ) was obtained from ATCC (LGC Standards GmbH, Wesel, Germany). Raji cells were maintained in RPMI-1640 (Seroglob), supplemented with 10\% FCS and 1\% (v/v) PSN (all from Sigma) (hereafter called 
"complete RPMI") at standard growth conditions. Raji cells were grown in $75 \mathrm{~cm}^{2}$ cell culture flasks (TPP) for 4 days and subcultured according to the cell bank protocol.

\section{Establishment of advanced intestinal co-cultures}

The advanced intestinal co-culture model is based on coculturing Caco- 2 and HT-29 cells with a predefined seeding ratio of 75:25 to achieve a confluent mucus layer. An overall cell seeding concentration of $2 \times 10^{4}$ cells $/ \mathrm{mm}^{2}$ for the apical compartment of different microporous membrane inserts (Corning ${ }^{\circledR}$ HTS Transwell ${ }^{\circledR}-96$ Tissue Culture Systems (pore size: $3 \mu \mathrm{m}$ ), ThinCert ${ }^{\mathrm{TM}}$ Tissue Culture Inserts 12-Well Greiner Bio-One (pore size: $3 \mu \mathrm{m}$ ) or ThinCert ${ }^{\mathrm{TM}}$ Tissue Culture Inserts 6-Well Greiner Bio-One (pore size: $3 \mu \mathrm{m})$ ) was maintained. The apical and the basolateral compartment were filled with complete DMEM and cells were allowed to differentiate under standard growth conditions for 14 days (Fig. 1). Medium was changed every other day. The addition of Raji B lymphocytes to Caco- 2 cells allows differentiation of Caco- 2 cells to M-cells (des Rieux et al. 2007). At day $145 \times 10^{5}$ Raji cells per Transwell ${ }^{\circledR}$ area of $113.1 \mathrm{~mm}^{2}$ were seeded in complete RPMI in the basolateral compartment. Similar to previous protocols Raji B lymphocytes were added to the basolateral compartment (Antunes et al. 2013; Brun et al. 2014; Lee et al. 2017; Mahler et al. 2012; Yu et al. 2020) and co-cultured for 48 h. At day 16 the Raji B lymphocytes were taken out of the basolateral compartment and advanced co-cultures were cultured for additional 5 days (total differentiation period: 21 days). Medium (apical: complete DMEM, basolateral: complete RPMI) was changed every other day.

\section{Treatment of advanced intestinal co-cultures with SAS}

Treatment volumes in the apical compartments of 6-, 12- and 96-well inserts were calculated to match medium heights of $5.2 \mathrm{~mm}$ in all well sizes in order to achieve identical dosing conditions. Therefore, the volume of SAS dispersions added to the apical side was $2.38 \mathrm{ml}$ for 6 -well inserts, $590 \mu \mathrm{l}$ for 12 -well inserts and $75 \mu \mathrm{l}$ for HTS 96-well inserts.
Basolateral volumes were $2 \mathrm{ml}$ for 6-well inserts, $1.5 \mathrm{ml}$ for 12-well inserts and $235 \mu \mathrm{l}$ for HTS 96-well inserts. Cells were treated in complete cell culture medium made from phenol red free DMEM (Gibco).

\section{Cell viability (MTT assay)}

Advanced intestinal co-cultures in HTS 96-well inserts were treated in the apical compartment with $0,3.125,6.25,12.5$, 25 or $50 \mu \mathrm{g} / \mathrm{ml}$ of SAS (for SIPERNAT ${ }^{\circledR} 22 \mathrm{~S}$ a higher concentration of $200 \mu \mathrm{g} / \mathrm{ml}$ was included) for $24 \mathrm{~h}$ and $48 \mathrm{~h}$. Amine modified polystyrene nanoparticles (PS-amine) (Bangs Laboratories, PA02N, Indiana, USA) were used as a particle positive control (Xia et al. 2006, 2008) at concentrations of $0,12.5,25,50,100$ and $200 \mu \mathrm{g} / \mathrm{ml}$ and added apically for $24 \mathrm{~h}$ and $48 \mathrm{~h}$. The chemical positive control cadmium sulphate $\left(\mathrm{CdSO}_{4}\right.$, Sigma) was added to the cells from the basolateral side in a concentration range from 0,1 , $10,100,1000$ and $10,000 \mu \mathrm{M}$. The basolateral compartment for all other treatments was filled with complete DMEM medium made from phenol red free medium (Gibco). All $0 \mu \mathrm{g} / \mathrm{ml}$ samples received an equivalent volume of water and served as solvent control. The MTT stock solution ( $5 \mathrm{mg} / \mathrm{ml}$ in PBS; Sigma, M5655) was diluted in complete DMEM made from phenol red free medium. $24 \mathrm{~h}$ and $48 \mathrm{~h}$ post-exposure the wells were washed twice with warm PBS before adding $0.5 \mathrm{mg} / \mathrm{ml}$ MTT. In the apical compartment a volume of $75 \mu \mathrm{l} /$ well and in the basal compartment of $235 \mu \mathrm{l} /$ well was added. The cells were incubated for $1.5 \mathrm{~h}$ at standard growth conditions. Afterwards cells in the apical compartment were lysed through the addition of $37.5 \mu \mathrm{l} 10 \%$ SDS in $0.01 \mathrm{M} \mathrm{HCl}$, the basal compartment was exchanged to an empty one. After overnight efficient lysis of the cell layer $60 \mu \mathrm{l}$ of the lysate was transferred to a standard 96-well plate and the absorbance was measured with a multi-well plate reader (Mithras ${ }^{2}$ LB943, Berthold Technologies) at $590 \mathrm{~nm}$. Interference analysis was performed at three different concentrations of SAS $(0.05,3.13$ and $50 \mu \mathrm{g} / \mathrm{ml})$ in one independent experiment with 2 technical replicates. None of the SAS quenched the formazan signal, reduced MTT to formazan or exhibited auto-absorption up to a concentration of $50 \mu \mathrm{g} / \mathrm{ml}$ (data not shown).

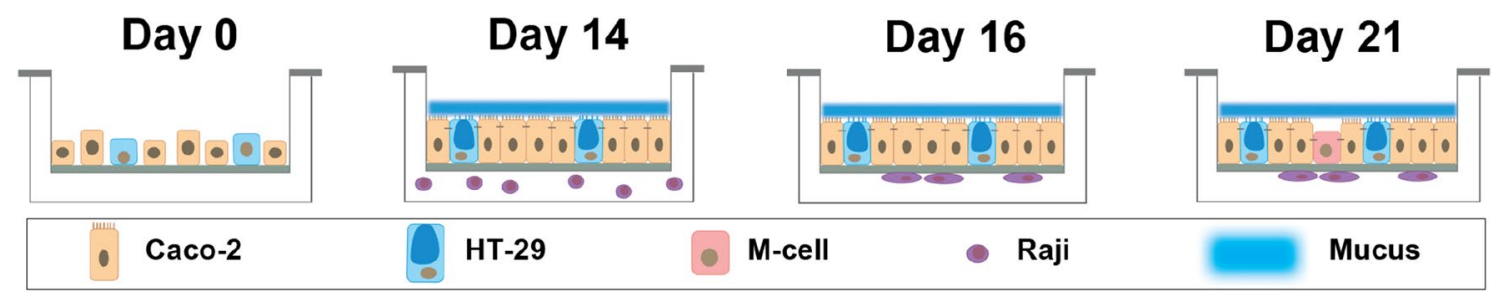

Fig. 1 Schematic of the cultivation of the advanced intestinal co-culture model 


\section{Measurement of transepithelial electrical resistance (TEER)}

The differentiation process of the advanced intestinal cocultures grown in 12- and 6-well inserts was evaluated by TEER measurements. The differentiation process was traced for one set of samples after every medium change and for all other cultures after 7, 14, 16 and 21 days using an Epithelia Voltohmmeter (EVOM) with sterilised STX2 electrodes (World precision, Instruments, Sarasota Florida, US). Only co-cultures with TEER values higher than $350 \Omega \mathrm{cm}^{2}$ were used for further experiments. The influence of SAS and PSamine treatment on TEER values was evaluated after $48 \mathrm{~h}$ right before the 12-well inserts were processed for subsequent analysis.

\section{Stainings}

\section{Alcian blue staining}

For the investigation of the mucus layer, an alcian blue staining was conducted. The 12-well inserts were fixed for $2 \mathrm{~h}$ with modified Carnoy solution $(60 \% \mathrm{EtOH}, 30 \%$ chloroform; $10 \%$ acetic acid) to preserve the mucin layer after $48 \mathrm{~h}$ of treatment of the advanced co-cultures with $50 \mu \mathrm{g} /$ $\mathrm{ml} \mathrm{SAS.} \mathrm{For} \mathrm{long-term} \mathrm{storage} \mathrm{the} \mathrm{inserts} \mathrm{were} \mathrm{immersed} \mathrm{in}$ $50 \% \mathrm{EtOH}$ and kept at $4{ }^{\circ} \mathrm{C}$. The inserts were stained with Alcian Blue 8GX (Sigma, 05,500) for 30 min before they were dehydrated and dried. For measurement in the plate reader the inserts were cut out of the insert holder and placed into a 24-well plate. Finally, absorbance was measured for 25 areas $(5 \times 5 \mu \mathrm{m}$ each $)$ per insert at $595 \mathrm{~nm}$ wavelength in a multi well plate reader (ELx800, BioTEX).

\section{Immunocytochemistry}

Advanced intestinal co-cultures in 12-well inserts after 21 days of culture were washed twice with PBS and fixed with $4 \%$ paraformaldehyde for $1 \mathrm{~h}$ at RT. The cells were washed with PBS and incubated with $30 \%$ sucrose at $4{ }^{\circ} \mathrm{C}$ overnight. Thereafter, cells were permeabilised with $0.1 \%$ Triton X-100 for 15 min, washed three times with PBS and non-specific binding sites were blocked for $30 \mathrm{~min}$ with 5\% bovine serum albumin (BSA) in PBS. Cells were incubated with Alexa Fluor ${ }^{\circledR} 488$ conjugated mouse anti-ZO-1 antibody (Invitrogen 339,188; 1:50), mouse anti-MUC5AC antibody (Sigma; M5293; 1:100) or rat anti-NKM 16-2-4 antibody (Miltenyi Biotec; 130-096-148; 1:100) in 1\% BSA in PBS at $4{ }^{\circ} \mathrm{C}$ overnight. After three washing steps in PBS, cells were incubated accordingly for $1 \mathrm{~h}$ with goat anti-rabbit Alexa Fluor® 555 (Invitrogen; A21428; 1:400), goat antimouse Alexa Fluor ${ }^{\circledR} 488$ (Invitrogen; A11029; 1:400) or goat anti-rat Alexa Fluor ${ }^{\circledR} 555$ (Invitrogen; A21434; 1:400) and phalloidin Alexa Fluor 633 (Invitrogen A22284; 1:50) in $1 \%$ BSA in PBS. After additional three washing steps in PBS, nuclei were counterstained with $1 \mu \mathrm{g} / \mathrm{ml}$ 4',6-diamidino-2-phenylindole (DAPI, Sigma D9542) in PBS for $10 \mathrm{~min}$ at RT. Inserts were carefully mounted with Mowiol $^{\circledR} 4-88$ (Sigma, 81,381) and covered with a glass coverslips. A confocal laser scanning microscope (Zeiss microscopes, Jena, Germany) with a C-Apochromat $40 \times / 1.2$ W Corr M27 objective was used to obtain z-stack images. The confocal pinhole was set to $1 \mathrm{AU}$ to optimise the $\mathrm{z}$-sectioning in the confocal mode.

\section{Alkaline phosphatase (ALP) activity assay}

For ALP activity assays, advanced intestinal co-cultures were treated with $50 \mu \mathrm{g} / \mathrm{ml} \mathrm{SAS}$ for $48 \mathrm{~h}$ in 6-well inserts. Aspirin $(10 \mu \mathrm{M})$ and trifluoperazine $(100 \mu \mathrm{M})$ were explored as potential positive controls. After the treatments, the inserts were washed with ice-cold PBS and $600 \mu \mathrm{l} /$ insert lysis buffer was added to the apical side (Cosín-Roger et al. 2013). The inserts were stored until further processing at $-20{ }^{\circ} \mathrm{C}$. To investigate the activity of the alkaline phosphatase the plates were thawed for $15 \mathrm{~min}$ at $600 \mathrm{rpm}$ on a shaker plate (Heidolph Titramax 101). The cell layer was detached with the help of a cell scraper and homogenised for $2 \mathrm{~min}$ in a sonification bath (Bandelin Sonorex Super $\mathrm{RK} 156 \mathrm{BH})$. The homogenate was centrifuged at $16,366 \mathrm{~g}$ at $4{ }^{\circ} \mathrm{C}$ for $30 \mathrm{~min}$. A p-nitrophenol (pNP; Sigma, 1048) standard curve was prepared with 0 and 4, 8, 12, 16, 20,30, $50 \mathrm{nmol} /$ well. The supernatants of the homogenates were diluted 1:40 in diethanolamine buffer and $80 \mu \mathrm{l}$ of this mixture was added to the wells of a 96-well plate. Additionally $50 \mu$ l of $5 \mathrm{mM}$ p-nitrophenylphosphate (pNPP; Sigma, 71,768 ) was added to all sample wells. The reaction was incubated for $30 \mathrm{~min}$ in the dark and stopped with $20 \mu \mathrm{l} 3 \mathrm{M}$ $\mathrm{NaOH}$. Absorbance was measured with a multi-well plate reader (Mithras ${ }^{2}$ LB943, Berthold Technologies) at $405 \mathrm{~nm}$. The total protein was determined with the Pierce ${ }^{\mathrm{TM}} \mathrm{BCA}$ Protein Assay Kit (Thermo Fischer, 23,225) according to the manufacturer's protocol. Interference analysis was performed at three different concentrations of SAS $(0.05,3.13$ and $50 \mu \mathrm{g} / \mathrm{ml}$ ) in one independent experiment with two technical replicates. None of the SAS quenched the pNP signal, reduced pNPP to pNP or exhibited auto-absorption up to a concentration of $50 \mu \mathrm{g} / \mathrm{ml}$ (data not shown).

\section{Lipid uptake}

To assess potential effects of SAS on lipid uptake, advanced intestinal co-cultures in 12-well inserts were treated with $50 \mu \mathrm{g} / \mathrm{ml} \mathrm{SAS} \mathrm{for} 48 \mathrm{~h}$. For the positive control investigations, $22 \mathrm{~d}$ differentiated co-cultures were treated with $50 \mu \mathrm{g} / \mathrm{ml}$ of the fatty acid synthase inhibitor 
C75 for $24 \mathrm{~h}$ (Accioly et al. 2008). After the treatment the medium was removed and the cultures were washed with PBS. Inserts were incubated for 10 min with $250 \mu \mathrm{l}$ of $20 \mu \mathrm{M}$ BODIPY ${ }^{\mathrm{TM}} 500 / 510 \mathrm{C} 1, \mathrm{C} 12$ (Thermo Fischer, D3823) in $0.1 \%$ BSA in PBS according to the manufacturer's protocol. Then inserts were washed with $500 \mu$ of ice cold $0.1 \%$ BSA in PBS and complete DMEM made from phenol red free medium was added to the apical $(590 \mu \mathrm{l})$ and basal $(1.5 \mathrm{ml})$ compartment. The cells were incubated for $1 \mathrm{~h}$ at standard growth conditions and the fluorescence was measured with a multi-well plate reader at $485 / 528 \mathrm{~nm}$ (excitation/emission).

\section{Iron uptake}

$72 \mathrm{~h}$ before the treatment of advanced intestinal co-cultures in 12-well inserts with SAS, $1 \mathrm{mg} / \mathrm{ml} \mathrm{SAS} \mathrm{was} \mathrm{pre-incu-}$ bated in 5\% BSA under standard growth conditions to establish a protein corona on the particles. Then the co-cultures were treated for $48 \mathrm{~h}$ with $50 \mu \mathrm{g} / \mathrm{ml}$ BSA-pre-coated SAS in iron free medium (phenol red free DMEM (Gibco) supplemented with $10 \mathrm{mM}$ PIPES, $11 \mu \mathrm{M}$ hydrocortison, $50 \mu \mathrm{g} /$ $\mathrm{ml}$ insulin, $0.02 \mu \mathrm{M}$ sodium selenite, $0.05 \mu \mathrm{M}$ triiodothyronine, $0.2 \mu \mathrm{g} / \mathrm{ml}$ EGF and 1\% (v/v) PSN (all from Sigma besides EGF which was ordered from Thermo Fischer)) (Christides et al. 2018; Perfecto et al. 2018). All inserts besides the background controls additionally received $30 \mu \mathrm{M}$ ferric ammonium citrate after the $48 \mathrm{~h}$ treatment with SAS. $2.5 \mathrm{mM} \mathrm{CaCl}_{2}$ or $600 \mu \mathrm{M}$ vitamin $\mathrm{C}$ in iron free medium were used as positive controls (Perfecto et al. 2018) and were added to untreated co-cultures during the final $24 \mathrm{~h}$. After incubation for another $24 \mathrm{~h}$ at standard growth conditions the inserts were washed with PBS, lysed with $200 \mu \mathrm{l}$ Cell Lytic M buffer (Sigma, C2978) and centrifuged at $14,000 \mathrm{~g}$ for $15 \mathrm{~min}$ at $4{ }^{\circ} \mathrm{C}$. The ferritin amount was measured with human Ferritin ELISA (Sigma, RAB0197) according to the manufacturer's protocol. In brief, the supernatant was diluted 1:2 in sample buffer and $100 \mu \mathrm{l} /$ well were added per well of a pre-coated 96-well plate. After a 2.5 -h incubation at RT the provided plate was washed and incubated for $1 \mathrm{~h}$ with detection antibody. The HRP-Streptavidin antibody was added for additional $45 \mathrm{~min}$. After $30 \mathrm{~min}$ of incubation with the ELISA Colorimetric TMB Reagent the reaction was stopped with the stop solution and absorbance was immediately measured in a multi-well plate reader (Mithras ${ }^{2}$, Berthold Technologies) at $450 \mathrm{~nm}$. Interference analysis was performed at $50 \mu \mathrm{g} /$ $\mathrm{ml}$ of SAS in one independent experiment with 2 technical replicates. None of the SAS showed intrinsic catalytic activity, influenced the optical density or bound to the antibodies or the antigen up to a concentration of $50 \mu \mathrm{g} / \mathrm{ml}$ (data not shown).

\section{Detection of cytokine release by ELISA}

After $24 \mathrm{~h}$ exposure to $50 \mu \mathrm{g} / \mathrm{ml} \mathrm{SAS,}, 200 \mu \mathrm{g} / \mathrm{ml} \mathrm{PS}$-amine or $10 \mathrm{ng} / \mathrm{ml}$ IL- $1 \beta$, the release of IL-8 and CCL2 was quantified in cell-free supernatants by ELISA. The cytokine amount was measured with human IL-8 ELISA (Invitrogen, 88-8086) and CCL2 ELISA (Invitrogen, 88-7399) according to the manufacturer's protocol. In brief, the supernatant was diluted 1:5 (IL-8) or 1:2 (CCL2) in phenol red free complete medium and $100 \mu \mathrm{l} /$ well were added. After a 2-h incubation at RT the plate was washed and incubated for $1 \mathrm{~h}$ with detection antibody. The avidin-HPR antibody was added for additional $30 \mathrm{~min}$ and then the reaction was developed with the substrate solution for another $15 \mathrm{~min}$ before it was stopped with $2 \mathrm{~N} \mathrm{H}_{2} \mathrm{SO}_{4}$. Absorbance was measured immediately in a multi-well plate reader (Mithras ${ }^{2}$, Berthold Technologies) at $450 \mathrm{~nm}$. Interference analysis was performed at 3.13 and $50 \mu \mathrm{g} / \mathrm{ml}$ of SAS in one independent experiment with two technical replicates. None of the SAS showed intrinsic catalytic activity, influenced the optical density or bound to the antibodies or the antigens up to a concentration of $50 \mu \mathrm{g} / \mathrm{ml}$ (data not shown).

\section{Statistics}

Results are presented as mean \pm standard deviations of three independent experiments, which were run with at least two technical replicates each. Statistical analysis was conducted with GraphPad Prism 8 software using a one-way analysis of variance (ANOVA; 95\% confidence interval) followed by the Dunnett's or Bonferroni's multiple comparisons test or Kruskal Wallis with Dunn's multiple comparisons test for the evaluation of the qPCR results.

\section{Results}

\section{SAS did not induce acute cytotoxicity in advanced intestinal co-cultures}

To assess the influence of SAS materials on the intestinal barrier in vitro, an advanced human intestinal co-culture model based on Caco-2/HT-29/Raji B cells (Fig. 1) was established and carefully characterized (Fig S1). The viability of the advanced intestinal co-cultures was determined after $24 \mathrm{~h}$ and $48 \mathrm{~h}$ of treatment with SAS using the MTT assay. All six SAS materials did not induce any decrease in cell viability below $86 \%$ after 48 h (Fig. 2 and S2). Four of the SAS materials (SIPERNAT ${ }^{\circledR} 350$, SIPERNAT $^{\circledR} 160$, SIPERNAT $^{\circledR} 50 \mathrm{~S}$ and AEROSIL ${ }^{\circledR}$ 380) even demonstrated a slight concentration-dependent increase in cell viability after $48 \mathrm{~h}$ of treatment (Fig. 2). For SIPERNAT ${ }^{\circledR} 22 \mathrm{~S}$, a higher concentration of $200 \mu \mathrm{g} / \mathrm{ml}$ was included since we previously observed a significant decrease in the viability of 


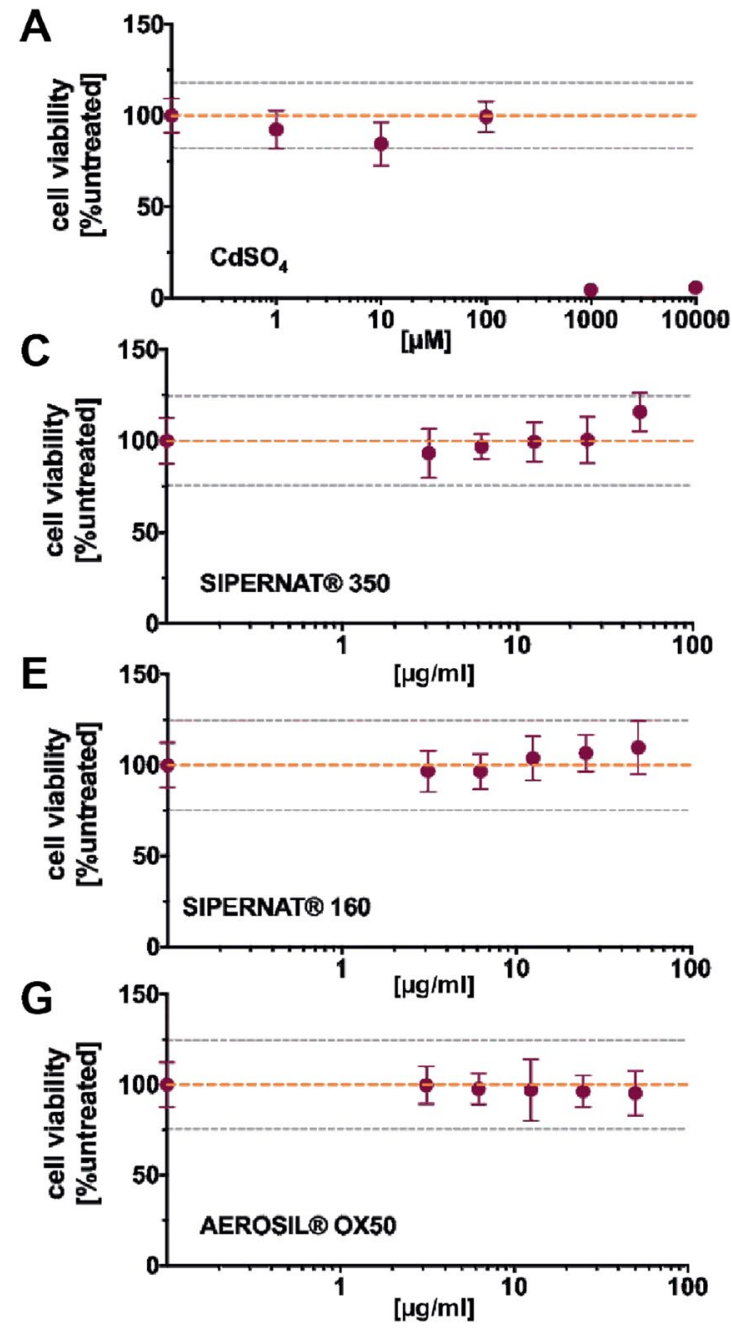

Fig. 2 Impact of SAS on cell viability of advanced intestinal co-cultures after $48 \mathrm{~h}$ of exposure. Following incubation of the advanced coculture model with various concentrations of different SAS for $48 \mathrm{~h}$ cell viability was assessed with the MTT assay. a $\mathrm{CdSO}_{4}$ served as a chemical positive control. b PS-amine was used as a particle positive control. c SIPERNAT $^{\circledR} 350$. d SIPERNAT ${ }^{\circledR} 22$ S. Here also a higher concentration of $200 \mu \mathrm{g} / \mathrm{ml}$ (hollow symbol) was applied. e SIPERNAT ${ }^{\circledR} 160$.

differentiated Caco- 2 cultures to $83 \%$ after $48 \mathrm{~h}$ exposure to $50 \mu \mathrm{g} / \mathrm{ml}$ (Hempt et al. 2020). Even at this high concentration, SIPERNAT ${ }^{\circledR} 22 \mathrm{~S}$ did not considerably decrease cell viability $(91 \pm 6.7 \%)$ in the advanced co-cultures after $48 \mathrm{~h}$. In contrast, $\mathrm{CdSO}_{4}$ significantly reduced cell viability in the co-cultures in a dose-dependent manner after $24 \mathrm{~h}$ and $48 \mathrm{~h}$ of exposure (Fig. 2 and S2). PS-amine particles were chosen due to previous reports that cationic amine-functionalised PS-particles are linked to cell death in other cell types (Hempt et al. 2020; Xia et al. 2008, 2006). However, in the advanced co-cultures containing a mucus barrier, no significant decrease in cell viability was detected up to a concentration of $200 \mu \mathrm{g} / \mathrm{ml}$ and $48 \mathrm{~h}$ of treatment with PS-amine.

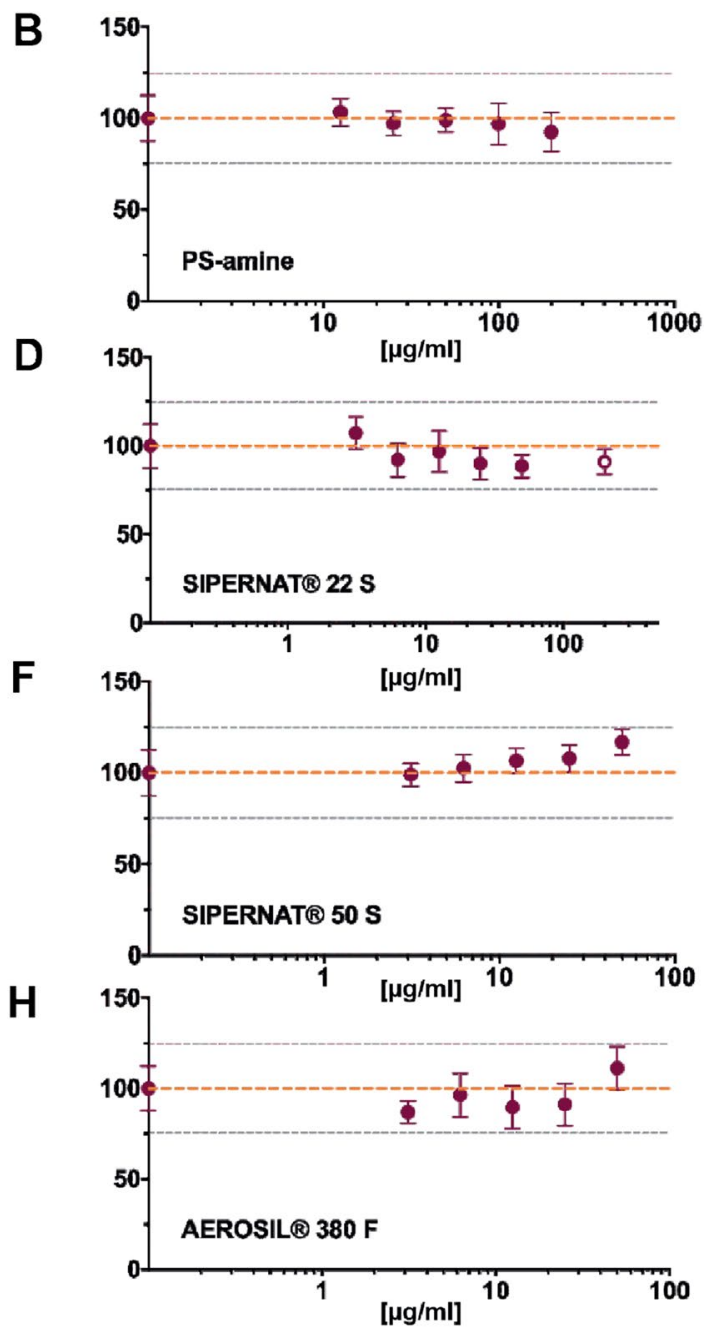

f SIPERNAT ${ }^{\circledR} 50 \mathrm{~S}$ g AEROSIL ${ }^{\circledR}$ OX50. h AEROSIL $^{\circledR} 380$ F. Mean values and corresponding standard deviations from three independent experiments with four technical replicates each are shown. The orange dashed line and the grey dotted lines resemble the mean value of the solvent control sample and twice the corresponding standard deviations, respectively. $* * * P \leq 0.001, * * * * P \leq 0.0001$ compared to the solvent control samples (colour figure online)

\section{SAS did not influence functional endpoints in advanced intestinal co-cultures besides iron uptake for two SAS materials}

\section{Barrier integrity}

To examine the potential effect of the SAS materials on the barrier integrity of advanced intestinal co-cultures, TEER values were determined after $48 \mathrm{~h}$ of exposure to $50 \mu \mathrm{g} /$ $\mathrm{ml}$ SAS. None of the six SAS materials induced significant changes in the TEER values compared to the solvent control (Fig. 3a). In contrast, $200 \mu \mathrm{g} / \mathrm{ml}$ PS-amine particles diminished TEER values by $-263.4 \pm 22.6 \Omega * \mathrm{~cm}^{2}$ as compared to solvent control $\mathrm{H}_{2} \mathrm{O}$. 

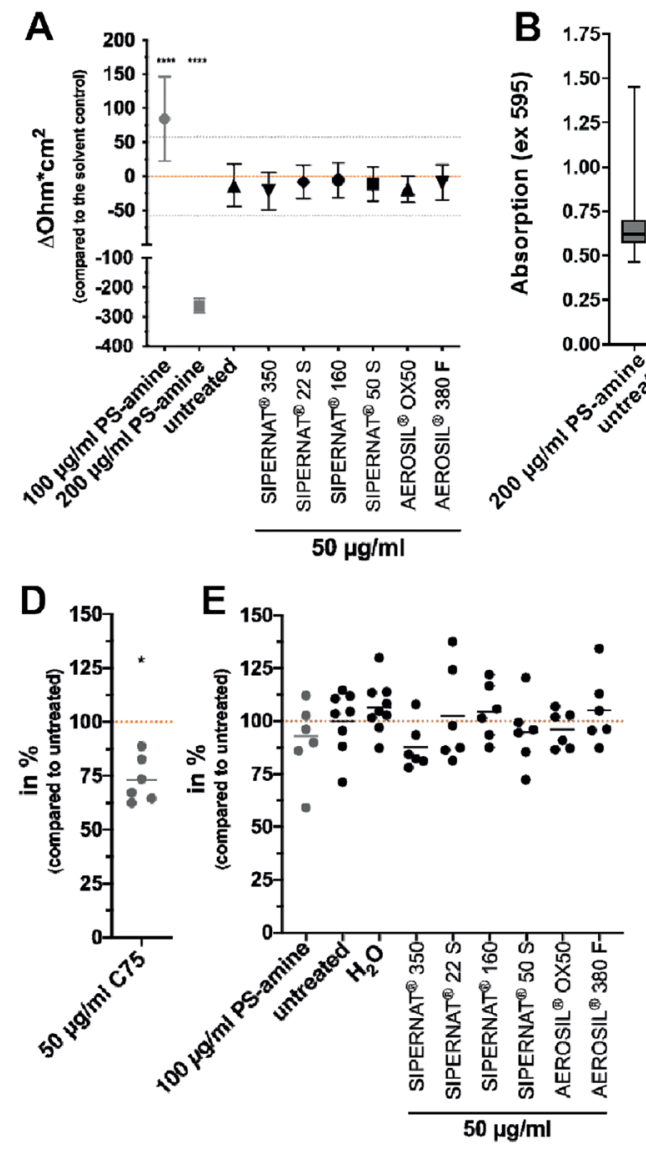

Fig. 3 Impact of SAS on physiological functions of the advanced intestinal co-cultures after 48 -h exposure including intestinal barrier integrity, mucus coverage, microvilli function as well as lipid and iron uptake. a After $48 \mathrm{~h}$ of treatment with $50 \mu \mathrm{g} / \mathrm{ml} \mathrm{SAS}$ and $200 \mu \mathrm{g} / \mathrm{ml}$ PS-amine TEER values were determined. Mean values and corresponding standard deviations for the SAS materials from six independent experiments and for PS-amine from three independent experiments with two technical replicates each are shown. The dashed orange lines and the grey dotted lines resemble the mean value of the solvent control sample and twice the corresponding standard deviations, respectively. b After incubation of the advanced co-culture with $50 \mu \mathrm{g} / \mathrm{ml}$ of the indicated SAS the mucus coverage was analysed by staining inserts with alcian blue and measuring absorption for 25 areas $(5 \times 5 \mu \mathrm{m}$ each $)$ per insert. Median, 25th and 75 th percentile values from three independent experiments with two technical replicates each are shown in the box-whiskers plots. c The activity of alkaline phosphatase (ALP) was assessed after the treatment of co-cultures with $50 \mu \mathrm{g} / \mathrm{ml} \mathrm{SAS}$ for $48 \mathrm{~h}$ by measuring the conversion of pNPP to pNP. $10 \mu \mathrm{M}$ aspirin, $100 \mu \mathrm{M}$ trifluoperazine and $200 \mu / \mathrm{ml}$ PS-amine were included as potential positive controls. Data points from three independent experiments performed in dupli-

\section{Mucus production and coverage}

The effect of SAS on mucus coverage of advanced intestinal co-cultures was evaluated by alcian blue staining and absorption measurements. No disruption of the mucus layer was apparent from visual inspection after treatment with $50 \mu \mathrm{g} / \mathrm{ml} \mathrm{SAS}$ for $48 \mathrm{~h}$ but slight differences in the intensity
C
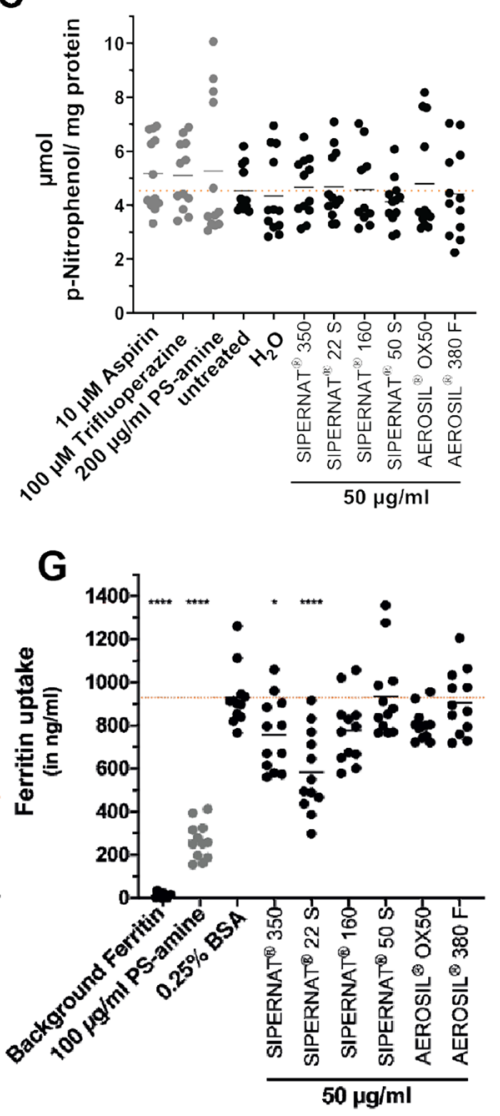

cates and measured in two technical replicates each are shown. Mean values of all data points are shown as horizontal lines. d The fatty acid synthase inhibitor C75 added at a concentration of $50 \mu \mathrm{g} / \mathrm{ml}$ for $24 \mathrm{~h}$ served as a chemical positive control for the investigation of lipid uptake. e After 48-h incubation of the advanced co-culture with the indicated SAS the lipid uptake was determined. Data points from three independent experiments performed in duplicates and measured in two technical replicates each are shown. Mean values of all data points are shown as horizontal lines. (D and E). f After a 24-h incubation of the advanced co-culture with $2.5 \mathrm{mM} \mathrm{CaCl}_{2}$ (iron uptake reducer) or $600 \mu \mathrm{M}$ vitamin $\mathrm{C}$ (iron uptake enhancer) the ferritin content in the cells was analysed. $\mathrm{g}$ After treatment with $50 \mu \mathrm{g} / \mathrm{ml} \mathrm{SAS}$ for $48 \mathrm{~h}$ the amount of ferritin in the cells was measured. Data points from three independent experiments performed in duplicates and measured in two technical replicates each are shown. Mean values of all data points are shown as horizontal lines. ( $F$ and $G)$. The dashed orange lines represent the mean values of solvent control samples (A, $\mathrm{F}, \mathrm{G})$ or untreated control samples $(\mathrm{C}, \mathrm{E}) . * P \leq 0.05$, $* * * * P \leq 0.0001$ compared to the solvent controls or untreated control samples (colour figure online)

of the stainings across the inserts made a comparison difficult. For a quantitative readout, we, therefore, measured the optical absorbance of 25 areas per each insert in a plate reader, which showed a broad distribution in the staining intensities. Nevertheless, median values in alcian blue staining were similar for the SAS treated cultures and the solvent control (Fig. 3b). Furthermore, we also assessed the impact 
of SAS on mucin production. MUC1 is one of the most studied membrane-associated mucins and is upregulated in the inflamed intestine (McAuley et al. 2007) and in ulcerative colitis in humans (Longman et al. 2006). The expression of the MUC1 gene was significantly downregulated after treatment with $200 \mu \mathrm{g} / \mathrm{ml}$ PS-amine for $24 \mathrm{~h}$ (Fig S3A). For the SAS materials, a decrease in $M U C 1$ expression was only observed after treatment with $50 \mu \mathrm{g} / \mathrm{ml}$ SIPERNAT ${ }^{\circledR} 160$ (Fig S3A). However, these effects were small with mean fold changes compared to the solvent control of $-1.72 \pm 1.56$ for PS amine and $-1.30 \pm 0.44$ for SIPERNAT ${ }^{\circledR} 160$.

\section{Alkaline phosphatase activity}

Alkaline phosphatase is present in the brush border of enterocytes and its activity has been exploited as a marker to confirm microvilli function and potential disruption of the microvilli layer (Fan et al. 1999; Miura et al. 1982). ALP activity was assessed after $48 \mathrm{~h}$ of exposure to $50 \mu \mathrm{g} / \mathrm{ml}$ SAS by measuring the turnover of p-nitrophenylphosphate to p-nitrophenol by alkaline phosphatase. None of the six SAS materials induced any significant changes in the alkaline phosphatase activity compared to the solvent control water or the untreated control (Fig. 3c). The values for all treatment varied considerably. The ALP activity assay has already been applied in previous studies, however, without including any positive controls in the Caco-2/HT-29 co-culture (Guo et al. 2017, 2018). Here, we explored the non-steroidal anti-inflammatory drug (NSAID) aspirin $(10 \mu \mathrm{M})$ and trifluoperazine $(100 \mu \mathrm{M})$ as potential controls since NSAID have been described to induce the ALP activity in rats (Sood et al. 2008) while trifluoperazine has been shown to decrease ALP activity in the rat intestine (Wang and Gilles-Baillien 1992). Both, aspirin and trifluoperazine did not affect ALP activity in the advanced co-culture and a suitable positive control remains to be identified. Gene expression levels of the ALP gene were below the detection limit of the qPCR and therefore could not be analysed.

\section{Lipid uptake}

The uptake of lipid components at the brush border of the enterocytes is an essential physiological function of the small intestine (Campbell et al. 2019). A lipid uptake assay, that is exploiting the fluorescent fatty acid analog BODIPY ${ }^{\mathrm{TM}} 500 / 510 \mathrm{C} 1, \mathrm{C} 12$ as a traceable model lipid, was performed to assess a potential impact of SAS on lipid uptake in advanced intestinal co-cultures. The fatty acid synthase inhibitor $\mathrm{C} 75$ has been described as a positive control in Caco-2 monocultures (Accioly et al. 2008). Treatment of advanced co-cultures with $50 \mu \mathrm{g} / \mathrm{ml} \mathrm{C75}$ for $24 \mathrm{~h}$ significantly reduced lipid uptake, confirming $\mathrm{C} 75$ as a positive control, also in mucus-expressing co-cultures (Fig. 3d). In contrast, the six SAS materials as well as PS-amine did not induce any significant differences in the uptake of the fluorescent lipid after $48 \mathrm{~h}$ (Fig. 3e).

To further confirm the absence of adverse effects on lipid uptake, we measured the gene expression levels of GPR120, a receptor for omega 3 fatty acids that is involved in antiinflammatory effects (Oh et al. 2010). GPR120 expression was significant increased after $24 \mathrm{~h}$ of treatment with $50 \mu \mathrm{g} /$ ml SIPERNAT ${ }^{\circledR} 350$ but downregulated for the untreated control compared to the solvent control (Fig S3B). The treatment with fatty acid synthase inhibitor C75 and the other SAS did not result in a gene expression change of the GPR120 gene.

\section{Iron uptake}

Ferritin uptake is a key physiological function exhibited by enterocytes in vivo (Campbell et al. 2019). The treatment with $2.5 \mathrm{mM}$ calcium chloride, an iron uptake inhibitor (Perfecto et al. 2018), showed a significant decrease in ferritin uptake in advanced intestinal co-cultures (Fig. 3f). The iron uptake enhancer vitamin C (Perfecto et al. 2018) significantly increased ferritin uptake in advanced co-cultures (Fig. 3f). Similarly, $100 \mu \mathrm{g} / \mathrm{ml}$ PS-amine induced a significant reduction in ferritin uptake compared to the solvent control $0.25 \%$ BSA. The treatment with the six SAS materials showed that SIPERNAT® 350 and SIPERNAT ${ }_{\circledast} 22 \mathrm{~S}$ reduce the ferritin uptake significantly in the advanced coculture (Fig. 3g).

To investigate if the changes of ferritin uptake after the treatment with the two SAS were also detectable with another pathway, the gene expression of the divalent metal transporter 1 (DMT1) was investigated. The divalent metal transporter DMT1 has been previously investigated to identify shifts in intestinal iron absorption (Zoller et al. 2001). The treatment of advanced co-cultures with $50 \mu \mathrm{g} / \mathrm{ml} \mathrm{SAS}$ materials did not result in a change in the gene expression of the DMT1 gene in comparison to the solvent control (Fig S3C). Only for the treatment with $200 \mu \mathrm{g} / \mathrm{ml}$ PS-amine a significant reduction in DMT1 gene expression was observed.

\section{SAS did not induce the release of the cytokines IL-8 and CCL2 in advanced intestinal co-cultures}

The release of the chemotactic and pro-inflammatory cytokines IL- 8 and CCL 2 was detected in the apical compartment after $24 \mathrm{~h}$ of treatment with the different SAS materials. None of the six SAS materials affected the release of the inflammatory cytokines IL- 8 and CCL2 compared to the solvent control $\mathrm{H}_{2} \mathrm{O}$ (Fig. 4). The treatment with the positive control IL- $1 \beta$ resulted in a significant increase in the secretion of both cytokines (Fig. 4). Only after exposure of advanced co-cultures with $200 \mu \mathrm{g} / \mathrm{ml}$ PS-amine, a slight 
A

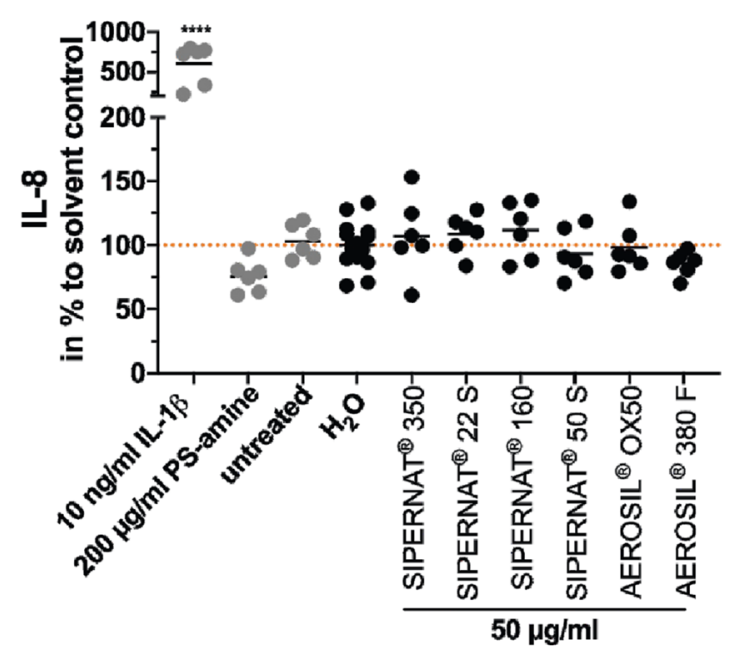

Fig. 4 Impact of SAS on the release of the inflammatory cytokines IL-8 and CCL2 in advanced intestinal co-cultures after $24 \mathrm{~h}$ of exposure. After $24 \mathrm{~h}$ incubation of the advanced co-culture with the indicated SAS the cytokine of IL-8 (a) and CCL2 (b) release was determined. The cytokine IL- $1 \beta$ at a concentration of $10 \mu \mathrm{g} / \mathrm{ml}$ for $24 \mathrm{~h}$ served as a chemical positive control. Data points from three inde-

tendency for decreased CCL2 levels was observed, which was however not statistically significant.

Similarly, gene expression levels of $I L-8$ were not altered after the treatment with the SAS materials for $24 \mathrm{~h}$ (Fig S3D). Stimulation with $10 \mathrm{ng} / \mathrm{ml} \mathrm{IL-1} \beta$ resulted in a significant increase in the gene expression of $I L-8$. Collectively, these data indicate that SAS do not have an acute effect on pro-inflammatory cytokine expression and secretion in advance intestinal co-cultures.

\section{Discussion}

Advanced intestinal co-culture models are more physiologically relevant than monoculture systems and were thus suggested to be superior for the safety assessment of ingested (nano)materials (García-Rodríguez et al. 2018b; Lehner et al. 2020; SaezTenorio et al. 2019; Sohal et al. 2020; Ude et al. 2017, 2019; Vila et al. 2018). Here, we applied a mucus-secreting intestinal co-culture model composed of Caco-2, HT-29 and Raji B cells as first reported by Schimpel et al. (2014). The mucus layer has previously been shown to constitute an essential physical-chemical barrier for many nanomaterials (Huck et al. 2019; Liu et al. 2014; Schneider et al. 2017) and should, therefore, be included in the evaluation of transport and effect studies of ingested food additives at the intestinal barrier. However, the presence of a mucus layer can be problematic for some conventional cytotoxicity assays due to limited penetration of reagents from or to the cells. For instance, we were not able to apply the

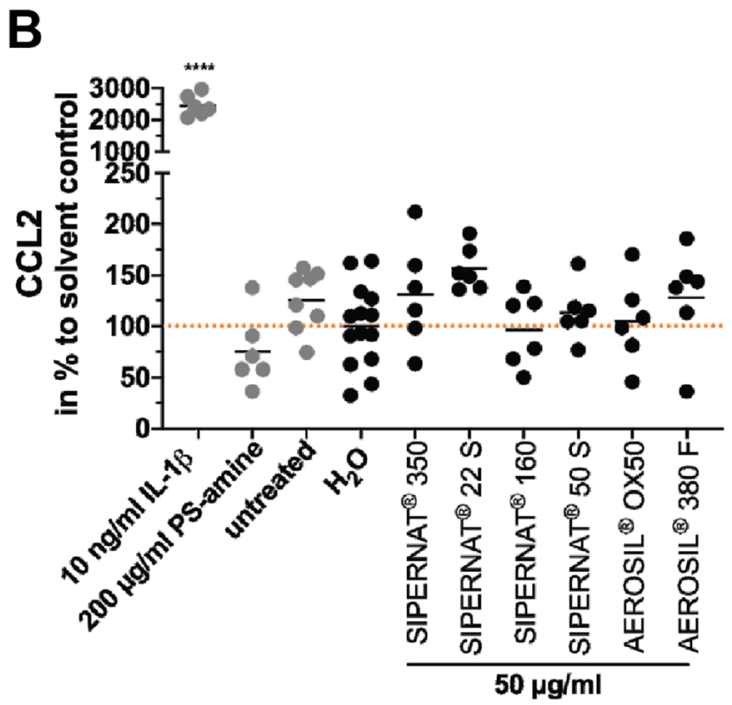

pendent experiments with two technical replicates each are shown. Mean values of all data points are shown as horizontal lines. The dashed orange lines resemble the mean value of the solvent control sample. ${ }^{*} P \leq 0.05, * * * * P \leq 0.0001$ compared to the solvent control (colour figure online)

resazurin viability assay to co-cultures most likely due to inefficient penetration and release of the resazurin/resorufin across the mucus layer (own unpublished data). Moreover, some positive assay controls that worked in the Caco-2 monocultures showed less pronounced effects (e.g., C75 or PS-amine) or did not work at all (aspirin or trifluoperazine) in the co-cultures (Hempt et al. 2020 and own unpublished data). Nevertheless, the following assays were compatible with mucus-secreting intestinal co-cultures including a positive chemical or particle control: MTT assay, TEER measurements, lipid and iron uptake assays as well as cytokine ELISA. For mucus coverage (alcian blue staining) and ALP activity, we did not yet succeed to identify a suitable positive control.

Besides a physiologically relevant biological model, it is important to use realistic in vitro dose ranges comparable to in vivo human exposures by integrating available human uptake data, knowledge of GIT physiology and computational in vitro dosimetry models (Sohal et al. 2018). For food-relevant SAS, estimated exposure doses for daily intake are $2.41 \mu \mathrm{g} / \mathrm{cm}^{2}$ (Sohal et al. 2020) or 0.02-11 $\mu \mathrm{g} /$ $\mathrm{cm}^{2}$ (Hempt et al. 2020). According to our previous study where we modelled the delivered dose for all the SAS materials (Hempt et al. 2020), the applied doses of $50 \mu \mathrm{g} /$ $\mathrm{ml}$ correspond to deposited doses of $11.8 \mu \mathrm{g} / \mathrm{cm}^{2}$ for SIPERNAT ${ }^{\circledR} 350,10.3 \mu \mathrm{g} / \mathrm{cm}^{2}$ for SIPERNAT ${ }^{\circledR} 22 \mathrm{~S}, 7.6 \mu \mathrm{g} /$ $\mathrm{cm}^{2}$ for SIPERNAT ${ }^{\circledR} 160,10 \mu \mathrm{g} / \mathrm{cm}^{2}$ for SIPERNAT ${ }^{\circledR} 50 \mathrm{~S}$, $6.1 \mu \mathrm{g} / \mathrm{cm}^{2}$ for AEROSIL ${ }^{\circledR}$ OX50 and $1.5 \mu \mathrm{g} / \mathrm{cm}^{2}$ for AEROSIL $^{\circledR} 380 \mathrm{~F}$ (Hempt et al. 2020), which are in a realistic exposure dose range. 
In our study, all investigated SAS materials did not affect cell viability/metabolic activity of the intestinal co-cultures after exposure up to $50 \mu \mathrm{g} / \mathrm{ml}$ for $48 \mathrm{~h}$. Similarly, the particle control PS-amine, which induced a slight cytotoxic response in differentiated Caco-2 monocultures (Hempt et al. 2020), did not decrease cell viability in the co-cultures, presumably due to the presence of a protective mucus layer. A decreased sensitivity in regards of cell viability and barrier integrity has previously been reported for other nanomaterials including silver, $\mathrm{SiO}_{2}$ and $\mathrm{CuO}$ nanoparticles when comparing the results of a Caco-2 monoculture with an intestinal coculture model (Cornu et al. 2020; Saez-Tenorio et al. 2019; Ude et al. 2019, 2017; Vila et al. 2018). However, a recent study found a considerable dose-dependent decrease in the viability/metabolic activity (PrestoBlue ${ }^{\mathrm{TM}}$ viability assay) of intestinal co-cultures treated with a food-grade SAS material (AEROSIL ${ }^{\circledR} 200 \mathrm{~F}$ ) compared to the Caco-2 monoculture (Sohal et al. 2020). The different outcome compared to our study could be due to slight differences in the experimental setup or characteristics of the applied SAS materials. For instance, AEROSIL ${ }^{\circledR} 200 \mathrm{~F}$ displayed a very slow settling rate (only $0.3 \%$ of the administered dose was delivered to the cells after $24 \mathrm{~h}$ ) (Sohal et al. 2020) whereas deposition was much higher for all of the six SAS materials investigated in this study (deposited fractions between 5 and 63\%) (Hempt et al. 2020).

Similar to the absence of adverse effects of SAS on cell viability, we did not observe any impact of the investigated SAS on barrier integrity. However, biological effects became apparent in some of the intestine-specific functional assays for selected SAS materials. For iron uptake, two of the SAS materials (SIPERNAT ${ }^{\circledR} 350$ and SIPERNAT ${ }^{\circledR} 22 \mathrm{~S}$ ) significantly reduced the uptake of ferritin after $48 \mathrm{~h}$ treatment with $50 \mu \mathrm{g} / \mathrm{ml}$ of the materials. However, this was not associated with a change in the expression of the divalent metal transporter 1 (DMT1), in contrast to the particle control PS-amine, which reduced both, ferritin uptake and DMTI expression. Adverse effects were also reported for $\mathrm{TiO}_{2}$ and $\mathrm{SiO}_{2}$ nanoparticles, which induced a significant decrease in iron transport but no change in iron uptake after $5 \mathrm{~d}$ chronic exposure in Caco-2/HT-29 co-cultures (Guo et al. 2018, 2017). Therefore, iron uptake and/or translocation may be prone to disturbance from different types of materials; however, there is no clear pattern as to which material properties could be responsible for these effects. For the SAS, the two types of materials that significantly reduced ferritin uptake had a relatively low specific surface area and were produced by precipitation, but two other SAS with equally low specific surface area (SIPERNAT ${ }^{\circledR} 160$ and AEROXIL ${ }^{\circledR}$ OX50) only showed a tendency for reduced ferritin uptake. It remains to be investigated whether the moderate effects of some SAS on ferritin uptake persist or if the cells develop adaptive responses.
Uptake of lipids was not compromised by any of the investigated SAS materials in the intestinal co-cultures after treatment with $50 \mu \mathrm{g} / \mathrm{ml}$ for $48 \mathrm{~h}$. This is in line with a previous study, which described that $30 \mathrm{~nm} \mathrm{SiO}_{2}$ nanoparticles reduced the uptake of lipids only after long-term exposure ( $5 \mathrm{~d}$ ) but not acute exposure (4 h) in Caco-2/HT-29 co-cultures (Guo et al. 2018). We further studied potential effects of SAS on the expression of the receptor for middle and long-schain fatty acids GPR120. This receptor was slightly upregulated only after exposure to SIPERNAT ${ }^{\circledR} 350$, which is a precipitated form of SAS with the lowest specific surface area of all investigated precipitated SAS materials. GPR 120 is known to influence glucose uptake and inflammation (Oh et al. 2010; Song et al. 2017; Zhang and Leung, 2014). However, we did not detect any significant changes in the release of the pro-inflammatory cytokines IL- 8 and CCL2 after treatment with SIPERNAT ${ }^{\circledR} 350$ or any other SAS material. Nevertheless, future studies are warranted to understand the effects of prolonged exposure to SIPERNAT ${ }^{\circledR} 350$ on lipid uptake.

Assessment of mucus coverage and production did not reveal adverse effects for most SAS despite a slight decrease of $M U C 1$ expression after $24 \mathrm{~h}$ of exposure to $50 \mu \mathrm{g} / \mathrm{ml}$ SIPERNAT $^{\circledR} 160$. MUC1 expression was also reduced by PS-amine but in both cases, this did not change the overall mucus coverage of the co-cultures even after $48 \mathrm{~h}$ of treatment. It is possible that the effect on $M U C 1$ expression was only transient as previously described for Caco-2/HT-29 cocultures treated with silver nanoparticles (Saez-Tenorio et al. 2019) or that other mucins present in the mucus layer could compensate for this decrease. Further studies are needed to understand if subtle effects on the mucus barrier might result in long-term consequences for intestinal barrier function.

Finally, none of the SAS materials affected the activity of ALP, suggesting that they do not affect microvilli layer integrity. However, since a suitable positive control is still lacking, it is unclear how sensitive this assay is to detect microvilli disruptions. In other studies, a significant increase in ALP activity has been detected for acute $(4 \mathrm{~h})$ and chronic $(5 \mathrm{~d})$ exposure of Caco-2/HT-29 co-cultures with $\mathrm{TiO}_{2}$ nanoparticles (Guo et al. 2017) or for chronic exposures with $\mathrm{SiO}_{2}$ nanoparticles (Guo et al. 2018). However, the latter work used non-food grade $20-30 \mathrm{~nm} \mathrm{SiO}{ }_{2}$ nanoparticles, which have highly distinct properties from the here studied SAS materials.

The six SAS material investigated in this study have been chosen to represent different production routes (wet and thermal), specific surface area (low, middle, large) and total silanol content (low, high). Pairs of SAS materials that vary in only one property are represented in this selection to investigate potential structure-activity relationships (SAR). A table summarising the biological effects of the different SAS has been compiled (Fig. 5) to aid the identification of potential SAR. 
One hypothesis of a SAR for SAS has been previously put forward by Zhang et al. (2012), who suggested that toxicity to bronchial epithelial (BEAS-2B) and macrophage (RAW 264.7) cells observed for fumed but not colloidal SAS was due to the presence of siloxane rings in fumed SAS. More recently, Rubio et al. (2019) confirmed that surface silanol content plays an important but not exclusive role in cellular toxicity and surface reactivity. They found that amorphous silica nanoparticles with lower total silanol content exhibited larger adverse cellular effects in RAW cells while normal small airway epithelial cells (SAEC) did not show any sign of toxicity (Rubio et al. 2019). In general, precipitated SAS materials have a higher total silanol content than pyrogenic (fumed) SAS (Fruijtier-Pölloth 2012; Zhang et al. 2012), which we also observed for the food relevant SAS used in this study. Nevertheless, differences in total silanol content did not correlate with the few observed biological responses in advanced intestinal co-cultures, probably due to limited penetration of the particles across the mucus layer. It has been recently shown that only a small fraction of the administered E 551 did cross a Caco-2/Raji co-culture in vitro (Yu et al. 2020) even in the absence of a mucus layer. Therefore, our findings further support a cell type-specific toxicity of SAS in dependence of total silanol content.

Regarding specific surface area of the SAS, we did not identify a clear correlation between this structural parameter and the observed biological responses in the intestinal co-cultures. SIPERNAT ${ }^{\circledR} 350$, with the lowest specific surface area showed some effects on iron uptake and expression of the receptor for middle and long chain fatty acids GPR120. However, AEROSIL ${ }^{\circledR}$ OX50, which was produced by a different production route (thermal) but has a similarly low specific surface area, did not induce any acute toxic response in intestinal cocultures. It is therefore possible that not a single characteristic but a combination of material properties is determining the biological activity, e.g. that only SAS with a small specific surface area and produced by a wet process interfere with iron uptake in intestinal cells. Due to the limited biological responses induced by the investigated SAS, it was not possible to identify further SAR for SAS in intestinal co-cultures.

Overall, we did not identify a single characteristic or a specific combination of properties that would be highly critical in regard to intestinal barrier impairment in vitro, and most of the studied SAS did not induce any adverse effects on a broad variety of functional endpoints.

\section{Conclusion}

Six food-relevant SAS materials were assessed for their short-term impact on the human intestinal barrier in vitro at concentrations relevant to dietary exposure. Despite considerable differences in specific surface area or silanol content, the investigated SAS did not affect cell viability, barrier integrity, inflammatory responses or microvilli function. These results are highly relevant for the hazard characterisation of $\mathrm{E} 551$ indicating a low risk for a negative biological response at the intact intestine from a short-term single exposure to food-relevant SAS, independent of the applied production route and the resulting variations in particle characteristics. Only slight effects regarding expression of $M U C 1$ and GPR120 as well as on iron uptake were observed for few SAS. Future studies including prolonged repeated exposures should address whether the induced alterations persist and could have a lasting impact on the integrity and function of the human intestinal barrier.

Previously formulated SAR between total silanol content and toxicity in monocytes was not confirmed for mucussecreting co-cultures in this study, indicating cell type specific responses probably due to the presence of a protective
Fig 5 Summary of the effects of the different SAS and PS-amine on advanced intestinal co-cultures. Shown are effects on different endpoints on functional (function) or gene expression level (mRNA) with: significant increase (green), in the range of the solvent control (light green) and significant decrease (red). n.d. $=$ not detectable (grey) (colour figure online)

\begin{tabular}{|c|c|c|c|c|c|c|c|c|}
\hline Endpoint & Material & 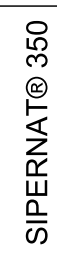 & 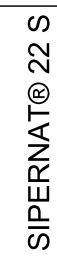 & 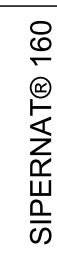 & 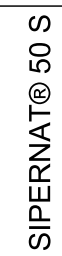 & 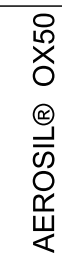 & 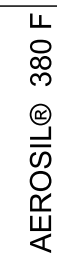 & 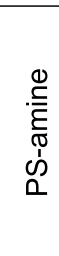 \\
\hline \multicolumn{9}{|l|}{ Viability } \\
\hline \multicolumn{2}{|l|}{ TEER } & & & & & & & $\downarrow$ \\
\hline \multirow{2}{*}{ inflammation (IL-8) } & cytokine & & & & & & & \\
\hline & mRNA & & & & & & & \\
\hline \multirow{2}{*}{ mucus } & function & & & & & & & \\
\hline & mRNA & & & $\downarrow$ & & & & $\downarrow$ \\
\hline \multirow{2}{*}{ microvilli } & function (ALP) & & & & & & & \\
\hline & mRNA & n.d. & n.d. & n.d. & n.d. & n.d. & n.d. & n.d. \\
\hline \multirow{2}{*}{ lipid } & function & & & & & & & \\
\hline & mRNA & $\uparrow$ & & & & & & \\
\hline \multirow{2}{*}{ iron } & function & $\downarrow$ & $\downarrow$ & & & & & $\downarrow$ \\
\hline & mRNA & & & & & & & $\downarrow$ \\
\hline
\end{tabular}


mucus layer and/or the absence of monocytes in the cultures. The mucus barrier might also have resulted in a reduced cytotoxicity of the particle control PS-amine in the advanced co-culture model as compared to Caco-2 monocultures (Hempt et al. 2020). These observations highlight that the role of the mucus layer on nanomaterial interactions with the intestinal barrier should be investigated in more detail, and that mucus-secreting co-cultures are indispensable for a more realistic toxicity assessment of ingested materials. In addition, our study corroborates that inclusion of additional intestine-specific functional endpoints should be a central part of any safety assessment of ingested materials at the intestinal barrier in vitro to cover the full range of potential adverse effects.

Acknowledgements The authors would like to acknowledge Pius Manser and Yvonne Elbs-Glatz for excellent technical support. We thank Leonie El Issawi-Frischknecht and Stefanie Guimond for the assistance with SEM. The authors would like to thank Juliane Obst for proofreading the manuscript.

Funding Open Access funding provided by Lib4RI - Library for the Research Institutes within the ETH Domain: Eawag, Empa, PSI \& WSL. We acknowledge funding from the NanoScreen Materials Challenge co-funded by the Competence Centre for Materials Science and Technology (CCMX). Furthermore, this research has been conducted with financial support from Evonik Industries AG.

Code availability Not applicable.

\section{Compliance with ethical standards}

Conflict of interest This research has been conducted with financial support from Evonik Industries AG.

Ethics approval Not applicable.

Consent to participate Not applicable.

Consent for publication Not applicable.

Availability of the data and material Not applicable.

Open Access This article is licensed under a Creative Commons Attribution 4.0 International License, which permits use, sharing, adaptation, distribution and reproduction in any medium or format, as long as you give appropriate credit to the original author(s) and the source, provide a link to the Creative Commons licence, and indicate if changes were made. The images or other third party material in this article are included in the article's Creative Commons licence, unless indicated otherwise in a credit line to the material. If material is not included in the article's Creative Commons licence and your intended use is not permitted by statutory regulation or exceeds the permitted use, you will need to obtain permission directly from the copyright holder. To view a copy of this licence, visit http://creativecommons.org/licenses/by/4.0/.

\section{References}

Accioly MT, Pacheco P, Maya-Monteiro CM, Carrossini N, Robbs BK, Oliveira SS, Kaufmann C, Morgado-Diaz JA, Bozza PT, Viola JPB (2008) Lipid bodies are reservoirs of cyclooxygenase-2 and sites of prostaglandin-E2 synthesis in colon cancer cells. Cancer Res 68:1732-1740. https://doi.org/10.1158/00085472.CAN-07-1999

Antunes F, Andrade F, Araújo F, Ferreira D, Sarmento B (2013) Establishment of a triple co-culture in vitro cell models to study intestinal absorption of peptide drugs. Eur J Pharm Biopharm 83:427-435. https://doi.org/10.1016/j.ejpb.2012.10.003

Assimakopoulos SF (2011) Enterocytes' tight junctions: from molecules to diseases. World J Gastrointest Pathophysiol 2:123. https ://doi.org/10.4291/wjgp.v2.i6.123

Atuma C, Strugala V, Allen A, Holm L (2001) The adherent gastrointestinal mucus gel layer: thickness and physical state in vivo. Am J Physiol Liver Physiol 280:G922-G929. https://doi.org/10.1152/ ajpgi.2001.280.5.G922

Bosch A, Maier M, Morfeld P (2012) Nanosilica? Clarifications are necessary! Nanotoxicology 6:611-613. https://doi. org/10.3109/17435390.2011.595837

Brandenberg N, Hoehnel S, Kuttler F, Homicsko K, Ceroni C, Ringel T, Gjorevski N, Schwank G, Coukos G, Turcatti G, Lutolf MP (2020) High-throughput automated organoid culture via stem-cell aggregation in microcavity arrays. Biomed Eng Nat. https://doi. org/10.1038/s41551-020-0565-2

Brun E, Barreau F, Veronesi G, Fayard B, Sorieul S, Chanéac C, Carapito C, Rabilloud T, Mabondzo A, Herlin-Boime N, Carrière M (2014) Titanium dioxide nanoparticle impact and translocation through ex vivo, in vivo and in vitro gut epithelia. Part Fibre Toxicol 11:13. https://doi.org/10.1186/1743-8977-11-13

Cabellos J, Delpivo C, Fernández-Rosas E, Vázquez-Campos S, Janer G (2017) Contribution of M-cells and other experimental variables in the translocation of $\mathrm{TiO} 2$ nanoparticles across in vitro intestinal models. NanoImpact 5:51-60. https://doi.org/10.1016/j. impact.2016.12.005

Campbell J, Berry J, Liang Y (2019) Chapter 71 - Anatomy and Physiology of the Small Intestine Shackelford's Surgery of the Alimentary Tract. Elsevier Inc, London

Chopra DP, Dombkowski AA, Stemmer PM, Parker GC (2010) Intestinal epithelial cells in vitro. Stem Cells Dev. https://doi. org/10.1089/scd.2009.0109

Christides T, Ganis JC, Sharp PA (2018) In vitro assessment of iron availability from commercial young child formulae supplemented with prebiotics. Eur J Nutr 57:669-678. https://doi.org/10.1007/ s00394-016-1353-3

Commission E (2008) Regulaiton (EC) No 1333/2008 on food additives. Off J Eur Union 354:16-33

Contado C, Ravani L, Passarella M (2013) Size characterization by sedimentation field flow fractionation of silica particles used as food additives. Anal Chim Acta 788:183-192. https://doi. org/10.1016/j.aca.2013.05.056

Cornu R, Chrétien C, Pellequer Y, Martin H, Béduneau A (2020) Small silica nanoparticles transiently modulate the intestinal permeability by actin cytoskeleton disruption in both Caco-2 and Caco-2/ HT29-MTX models. Toxicol Arch. https://doi.org/10.1007/s0020 4-020-02694-6

Cosín-Roger J, Ortiz-Masiá D, Calatayud S, Hernández C, Álvarez A, Hinojosa J, Esplugues JV, Barrachina MD (2013) M2 macrophages activate WNT signaling pathway in epithelial cells: relevance in ulcerative colitis. PLoS ONE 8:e78128. https://doi. org/10.1371/journal.pone.0078128 
EFSA (2015) Scientific opinion on the re-evaluation of octyl gallate (E 311) as a food additive. EFSA J. https://doi.org/10.2903/j. efsa.2015.4248

EFSA (2016a) Scientific opinion on the re-evaluation of gold (E 175) as a food additive. EFSA J. https://doi.org/10.2903/j.efsa.2016.4362

EFSA (2016b) Re-evaluation of titanium dioxide (E 171) as a food additive. EFSA J. https://doi.org/10.2903/j.efsa.2016.4545

EFSA (2016c) Scientific opinion on the re-evaluation of silver (E 174) as food additive. EFSA J. https://doi.org/10.2903/j.efsa.2016.4364

EFSA (2016d) Scientific Opinion on the re-evaluation of boric acid (E 284) and sodium tetraborate (borax) (E 285) as food additives. EFSA J. https://doi.org/10.2903/j.efsa.2013.3407

EFSA (2017a) Re-evaluation of lecithins (E 322) as a food additive. EFSA J. https://doi.org/10.2903/j.efsa.2017.4742

EFSA (2017b) Re-evaluation of sodium nitrate (E 251) and potassium nitrate (E 252) as food additives. EFSA J. https://doi. org/10.2903/j.efsa.2017.4787

EFSA (2018a) Scientific opinion on the re-evaluation of curcumin (E 100) as a food additive. EFSA J. https://doi.org/10.2903/j. efsa.2010.1679

EFSA (2018b) Scientific opinion on the re-evaluation of silicon dioxide (E 551) as a food additive. EFSA Journal. https://doi. org/10.2903/j.efsa.2018.5088

EU (2008) Verordnung (EG) Nr 1333/208 des Europäischen Parlaments über Lebensmittelzusatzstoffe. Amtsblatt der Europäischen Union, Newyork

Fan MZ, Adeola O, Asem EK (1999) Characterization of brush border membrane-bound alkaline phosphatase activity in different segments of the porcine small intestine. J Nutr Biochem 10:299-305. https://doi.org/10.1016/s0955-2863(99)00012-1

Fruijtier-Pölloth C (2012) The toxicological mode of action and the safety of synthetic amorphous silica-A nanostructured material. Toxicology 294:61-79. https://doi.org/10.1016/j.tox.2012.02.001

Fruijtier-Pölloth C (2016) The safety of nanostructured synthetic amorphous silica (SAS) as a food additive (E 551). Arch Toxicol 90:2885-2916. https://doi.org/10.1007/s00204-016-1850-4

García-Rodríguez A, Vila L, Cortés C, Hernández A, Marcos R (2018a) Exploring the usefulness of the complex in vitro intestinal epithelial model Caco-2/HT29/Raji-B in nanotoxicology. Food Chem Toxicol. https://doi.org/10.1016/j.fct.2018.01.042

García-Rodríguez A, Vila L, Cortés C, Hernández A, Marcos R (2018b) Effects of differently shaped TiO2NPs (nanospheres, nanorods and nanowires) on the in vitro model (Caco-2/HT29) of the intestinal barrier. Part Fibre Toxicol 15:33. https://doi. org/10.1186/s12989-018-0269-x

Giannasca PJ, Giannasca KT, Leichtner AM, Neutra MR (1999) Human intestinal M cells display the sialyl Lewis A antigen. Infect Immun 67:946-953

Guo Z, Martucci NJ, Moreno-Olivas F, Tako E, Mahler GJ (2017) Titanium dioxide nanoparticle ingestion alters nutrient absorption in an in vitro model of the small intestine. NanoImpact 5:70-82. https://doi.org/10.1016/j.impact.2017.01.002

Guo Z, Martucci NJ, Liu Y, Yoo E, Tako E, Mahler GJ (2018) Silicon dioxide nanoparticle exposure affects small intestine function in an in vitro model. Nanotoxicology 1:24. https://doi. org/10.1080/17435390.2018.1463407

Hempt C, Kaiser J-P, Scholder O, Buerki-Thurnherr T, Hofmann H, Rippl A, Schuster TB, Wick P, Hirsch C (2020) The impact of synthetic amorphous silica (E 551) on differentiated Caco-2 cells, a model for the human intestinal epithelium. Toxicol Vitr. https:// doi.org/10.1016/j.tiv.2020.104903

Hilgendorf C, Spahn-Langguth H, Regårdh CG, Lipka E, Amidon GL, Langguth P (2000) Caco-2 versus Caco-2/HT29-MTX co-cultured cell lines: permeabilities via diffusion, insideand outside-directed carrier-mediated transport. J Pharm Sci
89:63-75. https://doi.org/10.1002/(SICI)1520-6017(20000 1) $89: 1 \% 3 c 63::$ AID-JPS7\%3e3.0.CO;2-6

Huck BC, Hartwig O, Biehl A, Schwarzkopf K, Wagner C, Loretz B, Murgia X, Lehr CM (2019) Macro- and microrheological properties of mucus surrogates in comparison to native intestinal and pulmonary mucus. Biomacromol 20:3504-3512. https://doi. org/10.1021/acs.biomac.9b00780

IPTS EC (2007) Integrated pollution prevention and control reference document on best available techniques for the manufacture of large volume inorganic chemicals - solids and others industry. Brus Belgium Ipts/Ec I:300-339

Jumarie C, Malo C (1991) Caco-2 cells cultured in serum-free medium as a model for the study of enterocytic differentiation in vitro. $\mathbf{J}$ Cell Physiol 149:24-33. https://doi.org/10.1002/jcp.1041490105

Kucki M, Diener L, Bohmer N, Hirsch C, Krug HF, Palermo V, Wick $P$ (2017) Uptake of label-free graphene oxide by Caco-2 cells is dependent on the cell differentiation status. J Nanobiotechnology 15:1-18. https://doi.org/10.1186/s12951-017-0280-7

Lea $T$ (2015) Caco-2 cell line, in: the impact of food bioactives on health. Springer, Cham

Lee J-A, Kim M-K, Song JH, Jo M-R, Yu J, Kim K-M, Kim Y-R, Oh J-M, Choi S-J (2017) Biokinetics of food additive silica nanoparticles and their interactions with food components. Colloids Surf B Biointerf 150:384-392. https://doi.org/10.1016/j.colsu rfb.2016.11.001

Lehner R, Wohlleben W, Septiadi D, Landsiedel R, Petri-Fink A, Rothen-Rutishauser B (2020) A novel 3D intestine barrier model to study the immune response upon exposure to microplastics. Toxicol Arch. https://doi.org/10.1007/s00204-020-02750-1

Liu M, Zhang J, Shan W, Huang Y (2014) Developments of mucus penetrating nanoparticles. Asian J Pharm Sci 10:275-282. https ://doi.org/10.1016/j.ajps.2014.12.007

Livak KJ, Schmittgen TD (2001) Analysis of relative gene expression data using real-time quantitative PCR and the 2(-Delta Delta C(T)) Method. Methods San Diego Calif 25:402-408

Longman RJ, Poulsom R, Corfield AP, Warren BF, Wright NA, Thomas MG (2006) Alterations in the composition of the supramucosal defense barrier in relation to disease severity of ulcerative colitis. J Histochem Cytochem 54:1335-1348. https://doi. org/10.1369/jhc.5A6904.2006

Mabbott NA, Donaldson DS, Ohno H, Williams IR, Mahajan A (2013) Microfold (M) cells: Important immunosurveillance posts in the intestinal epithelium. Mucosal Immunol. https://doi.org/10.1038/ mi.2013.30

Mahler GJ, Esch MB, Tako E, Southard TL, Archer SD, Glahn RP, Shuler ML (2012) Oral exposure to polystyrene nanoparticles affects iron absorption. Nat Nanotechnol 7:264-271. https://doi. org/10.1038/nnano.2012.3

Maier M, Babick F, Retamal Marin RR, Stintz M (2013) Does nanostructured synthetic amorphous silica disintegrate after oral uptake? Toxicologist 1:6-13

Maynard AD (2014) Old materials, new challenges? Nat Nanotechnol. https://doi.org/10.1038/nnano.2014.196

McAuley JL, Linden SK, Chin WP, King RM, Pennington HL, Gendler SJ, Florin TH, Hill GR, Korolik V, McGuckin MA (2007) MUC1 cell surface mucin is a critical element of the mucosal barrier to infection. J Clin Invest 117:2313-2324. https://doi.org/10.1172/ JCI26705

Miura S, Asakura H, Morishita T, Hibi T, Munakata Y, Kobayashi K, Tsuchiya M (1982) Changes in intestinal alkaline phosphatase activity in cholera toxin-treated rats. Gut 23:507-512. https://doi. org/10.1136/gut.23.6.507

OECD (2004) Synthetic amorphous silica and silicates, SIDS initial assessment report for SIAM 19. Berlin, Germany

Oh DY, Talukdar S, Bae EJ, Imamura T, Morinaga H, Fan WQ, Li P, Lu WJ, Watkins SM, Olefsky JM (2010) GPR120 is an omega-3 fatty 
acid receptor mediating potent anti-inflammatory and insulinsensitizing effects. Cell 142:687-698. https://doi.org/10.1016/j. cell.2010.07.041

Owen R, Ermak T (1990) Structural specializations for antigen uptake and processing in the digestive tract. Springer Semin Immunopathol 12:139-152. https://doi.org/10.1007/BF00197502

Perfecto A, Rodriguez-Ramiro I, Rodriguez-Celma J, Sharp P, Balk J, Fairweather-Tait S (2018) Pea ferritin stability under gastric $\mathrm{pH}$ conditions determines the mechanism of iron uptake in Caco-2 cells. J Nutr 148:1229-1235. https://doi.org/10.1093/jn/nxy096

Powell JJ, Faria N, Thomas-McKay E, Pele LC (2010) Origin and fate of dietary nanoparticles and microparticles in the gastrointestinal tract. J Autoimmun 34:J226-J233. https://doi.org/10.1016/j. jaut.2009.11.006

Rieux A, Fievez V, Théate I, Mast J, Préat V, Schneider Y-J (2007) An improved in vitro model of human intestinal follicle-associated epithelium to study nanoparticle transport by M cells. Eur J Pharm Sci 30:380-391. https://doi.org/10.1016/j.ejps.2006.12.006

Rubio L, Pyrgiotakis G, Beltran-Huarac J, Zhang Y, Gaurav J, Deloid G, Spyrogianni A, Sarosiek KA, Bello D, Demokritou P (2019) Safer-by-design flame-sprayed silicon dioxide nanoparticles: the role of silanol content on ROS generation, surface activity and cytotoxicity. Fibre Toxicol Part. https://doi.org/10.1186/s1298 9-019-0325-1

Saez-Tenorio M, Domenech J, García-Rodríguez A, Velázquez A, Hernández A, Marcos R, Cortés C (2019) Assessing the relevance of exposure time in differentiated Caco-2/HT29 cocultures. Effects of silver nanoparticles. Food Chem Toxicol 123:258-267. https://doi.org/10.1016/j.fct.2018.11.009

Sato T, Vries RG, Snippert HJ, van de Wetering M, Barker N, Stange DE, van Es JH, Abo A, Kujala P, Peters PJ, Clevers H (2009) Single Lgr5 stem cells build crypt-villus structures in vitro without a mesenchymal niche. Nature 459:262-265. https://doi.org/10.1038/ nature 07935

Schimpel C, Teubl B, Absenger M, Meindl C, Fröhlich E, Leitinger G, Zimmer A, Roblegg E (2014) Development of an advanced intestinal in vitro triple culture permeability model to study transport of nanoparticles. Mol Pharm 11:808-818. https://doi.org/10.1021/ mp400507g

Schneider A, Feussner H (2017) Anatomy, physiology, and selected pathologies of the gastrointestinal tract. Biomed Eng Gastrointest Surg. https://doi.org/10.1016/b978-0-12-803230-5.00002-6

Schneider CS, Xu Q, Boylan NJ, Chisholm J, Tang BC, Schuster BS, Henning A, Ensign LM, Lee E, Adstamongkonkul P, Simons BW, Wang SYS, Gong X, Yu T, Boyle MP, Suk JS, Hanes J (2017) Nanoparticles that do not adhere to mucus provide uniform and long-lasting drug delivery to airways following inhalation. Sci Adv. https://doi.org/10.1126/sciadv.1601556

Shearman DJC, Muir AR (1960) Observations on the secretory cycle of goblet cells. Q J Exp Physiol Cogn Med Sci 45:337-342. https ://doi.org/10.1113/expphysiol.1960.sp001488

Shroyer NF, Kocoshis SA (2011) Anatomy and Physiology of the Small and Large Intestines, pediatric gastrointestinal and liver disease. Elsevier, Newyork

Sigurdsson HH, Kirch J, Lehr C-M (2013) Mucus as a barrier to lipophilic drugs. Int J Pharm 453:56-64. https://doi.org/10.1016/J. IJPHARM.2013.05.040

Sohal IS, O'Fallon KS, Gaines P, Demokritou P, Bello D (2018) Ingested engineered nanomaterials: state of science in nanotoxicity testing and future research needs. Part Fibre Toxicol 15:29. https://doi.org/10.1186/s12989-018-0265-1

Sohal IS, DeLoid GM, O'Fallon KS, Gaines P, Demokritou P, Bello D (2020) Effects of ingested food-grade titanium dioxide, silicon dioxide, iron (III) oxide and zinc oxide nanoparticles on an in vitro model of intestinal epithelium: comparison between monoculture vs a mucus-secreting coculture model. NanoImpact 17:100209. https://doi.org/10.1016/j.impact.2020.100209

Song T, Yang Y, Zhou Y, Wei H, Peng J (2017) GPR120: a critical role in adipogenesis, inflammation, and energy metabolism in adipose tissue. Cell Mol Life Sci 12:23-34. https://doi.org/10.1007/s0001 8-017-2492-2

Sood N, Kaushal N, Sanyal SN (2008) Effect of different non-steroidal anti-inflammatory drugs, aspirin, nimesulide and celecoxib on the disaccharide hydrolases and histoarchitecture of the rat intestinal brush border membrane. Nutr Hosp 23:326-331. https://doi. org/10.3305/nutr

Ude VC, Brown DM, Viale L, Kanase N, Stone V, Johnston HJ (2017) Impact of copper oxide nanomaterials on differentiated and undifferentiated Caco-2 intestinal epithelial cells; assessment of cytotoxicity, barrier integrity, cytokine production and nanomaterial penetration. Part Fibre Toxicol 14:31. https://doi.org/10.1186/ s12989-017-0211-7

Ude VC, Brown DM, Stone V, Johnston HJ (2019) Using 3D gastrointestinal tract in vitro models with microfold cells and mucus secreting ability to assess the hazard of copper oxide nanomaterials. J Nanobiotechnology 17:70. https://doi.org/10.1186/s1295 1-019-0503-1

Van der Zande M, Vandebriel RJ, Groot MJ, Kramer E, Herrera Rivera ZE, Rasmussen K, Ossenkoppele JS, Tromp P, Gremmer ER, Peters RJB, Hendriksen PJ, Marvin HJP, Hoogenboom RLAP, Peijnenburg AACM, Bouwmeester H (2014) Sub-chronic toxicity study in rats orally exposed to nanostructured silica. Part Fibre Toxicol 11:1-19. https://doi.org/10.1186/1743-8977-11-8

Van Kesteren PCE, Cubadda F, Bouwmeester H, Van Eijkeren JCH, Dekkers S, De Jong WH, Oomen AG (2015) Novel insights into the risk assessment of the nanomaterial synthetic amorphous silica, additive E551, in food. Nanotoxicology 9:442-452. https ://doi.org/10.3109/17435390.2014.940408

Vila L, García-Rodríguez A, Cortés C, Marcos R, Hernández A (2018) Assessing the effects of silver nanoparticles on monolayers of differentiated Caco- 2 cells, as a model of intestinal barrier. Food Chem Toxicol 116:1-10. https://doi.org/10.1016/j.fct.2018.04.008

Wang H, Gilles-Baillien M (1992) Alkaline phosphatase and ATPases in brush-border membranes of rat jejunum: Distinct effects of divalent cations and of some inhibitors. Arch Physiol Biochem 100:289-294. https://doi.org/10.3109/13813459208998117

Xia T, Kovochich M, Brant J, Hotze M, Sempf J, Oberley T, Sioutas C, Yeh JI, Wiesner MR, Nel AE (2006) Comparison of the abilities of ambient and manufactured nanoparticles to induce cellular toxicity according to an oxidative stress paradigm. Nano Lett. https://doi.org/10.1021/n1061025k

Xia T, Kovochich M, Liong M, Zink JI, Nel AE (2008) Cationic polystyrene nanosphere toxicity depends on cell-specific endocytic and mitochondrial injury pathways. ACS Nano. https://doi. org/10.1021/nn700256c

Yu J, Kim YH, Kim HM, Oh JM, Kim YR, Choi SJ (2020) Determination of the fate and biological responses of food additive silica particles in commercial foods. Food Chem. https://doi. org/10.1016/j.foodchem.2020.127304

Zhang D, Leung PS (2014) Potential roles of GPR120 and its agonists in the management of diabetes. Devel Ther Drug Des. https://doi. org/10.2147/DDDT.S53892

Zhang H, Dunphy DR, Jiang X, Meng H, Sun B, Tarn D, Xue M, Wang X, Lin S, Ji Z, Li R, Garcia FL, Yang J, Kirk ML, Xia T, Zink JI, Nel A, Brinker CJ (2012) Processing pathway dependence of amorphous silica nanoparticle toxicity: colloidal vs pyrolytic. J Am Chem Soc. https://doi.org/10.1021/ja304907c

Zoller H, Koch RO, Theurl I, Obrist P, Pietrangelo A, Montosi G, Haile DJ, Vogel W, Weiss G (2001) Expression of the duodenal iron transporters divalent-metal transporter 1 and ferroportin 1 in iron 
deficiency and iron overload. Gastroenterology 120:1412-1419. https://doi.org/10.1053/gast.2001.24033
Publisher's Note Springer Nature remains neutral with regard to jurisdictional claims in published maps and institutional affiliations. 